This item was submitted to Loughborough's Research Repository by the author.

Items in Figshare are protected by copyright, with all rights reserved, unless otherwise indicated.

\title{
Using a 'value-added' approach for contextual design of geographic information
}

PLEASE CITE THE PUBLISHED VERSION

http://dx.doi.org/10.1016/j.apergo.2012.10.012

PUBLISHER

(C) Elsevier Ltd and The Ergonomics Society

VERSION

AM (Accepted Manuscript)

LICENCE

CC BY-NC-ND 4.0

REPOSITORY RECORD

May, Andrew. 2019. “Using a 'value-added' Approach for Contextual Design of Geographic Information”. figshare. https://hdl.handle.net/2134/12007. 
This item was submitted to Loughborough's Institutional Repository (https://dspace.lboro.ac.uk/) by the author and is made available under the following Creative Commons Licence conditions.

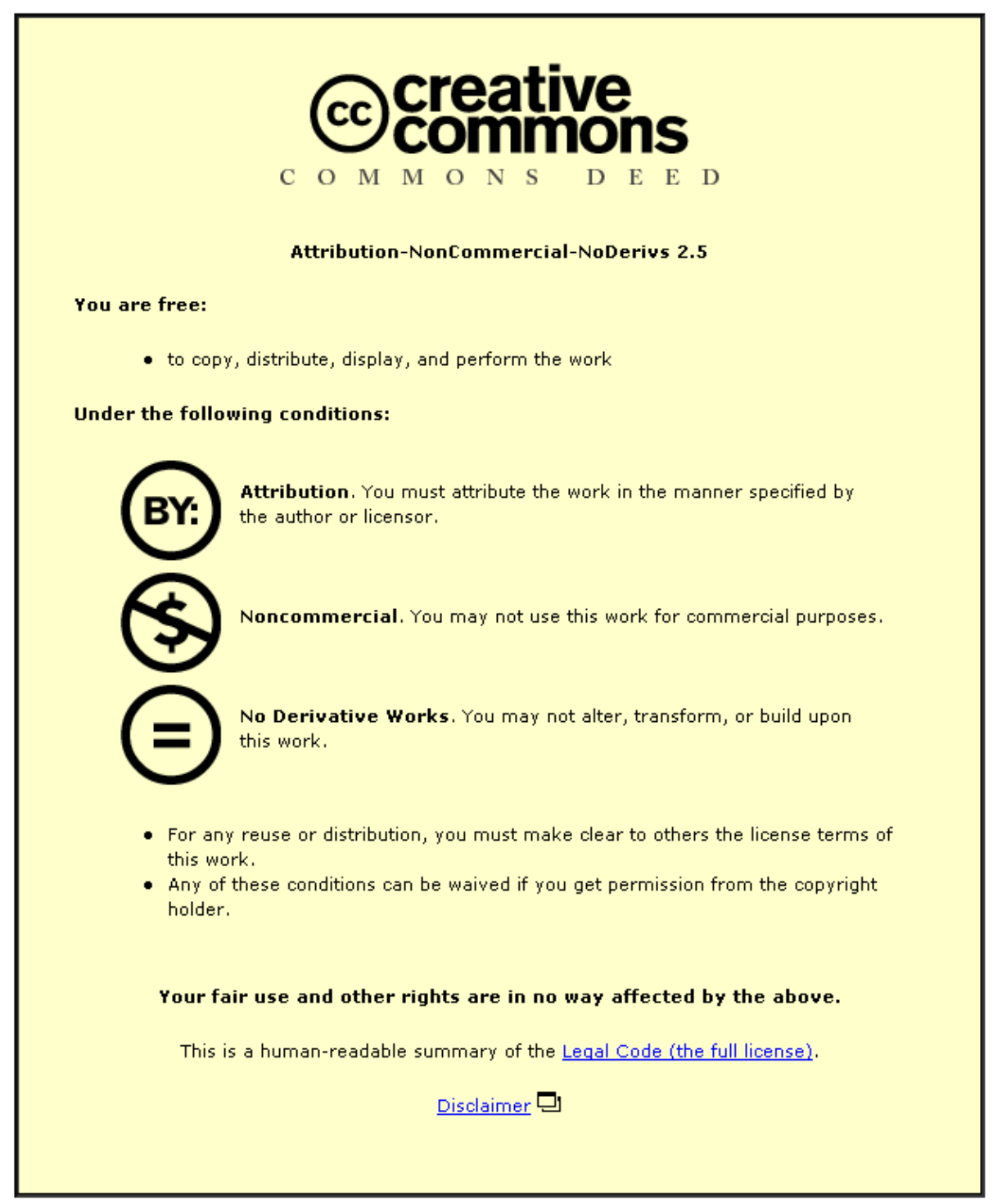

For the full text of this licence, please go to: http://creativecommons.org/licenses/by-nc-nd/2.5/ 


\title{
Using a 'value-added' approach for contextual design of geographic information
}

\author{
Andrew May \\ Design School, Loughborough University, Ashby Road, Loughborough, LE11 3TU \\ a.j.may@lboro.ac.uk \\ +44 1509226906 (phone) \\ +44 1509226960 (fax)
}

\begin{abstract}
The aim of this article is to demonstrate how a 'value-added' approach can be used for user-centred design of geographic information. An information science perspective was used, with value being the difference in outcomes arising from alternative information sets. Sixteen drivers navigated a complex, unfamiliar urban route, using visual and verbal instructions representing the distance-to-turn and junction layout information presented by typical satellite navigation systems. Data measuring driving errors, navigation errors and driver confidence were collected throughout the trial. The results show how driver performance varied considerably according to the geographic context at specific locations, and that there are specific opportunities to add value with enhanced geographical information. The conclusions are that a value-added approach facilitates a more explicit focus on 'desired' (and feasible) levels of end user performance with different information sets, and is a potentially effective approach to user-centred design of geographic information.
\end{abstract}

\section{Keywords}

Information Value, Geographic Information, Vehicle Navigation, UCD, Added-Value 


\section{Introduction}

\subsection{Background}

Advances in digital mapping, positioning, communications networks and highly portable computing devices are enabling increasingly ubiquitous access to geographic information. There is now a wide range of commercially available location-aware products and services that enable individuals to use geographic information for work or leisure purposes. Vehicle Navigation Systems are one such example of mobile computing that is now commonplace in modern vehicles, either as original manufacturer fitment, aftermarket personal navigation device, or as an application on a smartphone. They use positioning technologies and a navigable map database to provide turn-by-turn and/or map-based information to a driver to enable them to navigate to an unfamiliar destination. Walker et al. (2001) describe how Vehicle Navigation Systems 'facilitate more rational use of the road network by offering drivers decision support'. From a geographic perspective, they are a technical system falling under the broad category of data dissemination (Goodchild, 2009).

Over two decades ago, Lunenfeld (1989) and Wierwille et al. (1989) identified a range of human factors issues with Vehicle Navigation Systems. Since then, a number of authors have addressed issues to do with their user-centred design (Lavie et al., 2011; Kun et al., 2009; May and Ross, 2006; Lansdown et al., 2004; Burnett, 2000; Jackson, 1998; Burns, 1998; Green et al., 1995; Fastenmeier et al., 1994).

Most human factors research has taken a safety/usability approach, incorporating measures of driver and vehicle performance. Indeed there has been recent effort to generate a usability evaluation framework and toolkit for in-vehicle information systems (Harvey et al., 2011). However, a limitation of a usability perspective is that it does not place explicit focus on the link between presentation of information to the driver (from within and outside of the vehicle) and drivers' decisions and actions at specific manoeuvres.

An alternative (or complementary approach) to the design of in-vehicle information systems such as vehicle navigation is to treat them as decision support systems. Rather than being an interface, they are treated as one of several sources of information, used by drivers to make routing decisions at points of navigational uncertainty. The 'decision support system' is being used in the presence or absence of a wide range of 
other geographic information cues that will have impact on the navigation decisions and courses of action that drivers take.

The key difference between a decision support system used within a vehicle and those used in more traditional environments such as financial planning, medical diagnosis and operational research is that with in-vehicle systems the interaction with the device is not usually the primary task of the driver. Simply providing more navigation information at driver decision points does not necessarily benefit the driver, due to the multitasking environment (Fastreza and Haue, 2008) and the limited processing resources that humans have. Research into how humans benefit from geographic information has shown that 'less' can be 'more' (Meilinger et al., 2007). However there is a current trend for greater complexity of navigation interfaces, an example being the move towards presentation of 3D or photo-realistic views of the terrain, as highlighted by Kun et al. (2009). This potentially conflicts with the point highlighted by authors such as Marcus (2004) - the need for safe, simple and direct navigation instructions.

\subsection{Aims of study}

The overall aim of this study is to present an alternative perspective on the usercentred design of geographic information that takes into account the wider geographical context that such systems operate within. More specifically, the study uses a 'value-adding' framework to help understand how geographical information provides benefit to drivers navigating an unfamiliar route. The intention of the article is to introduce a new approach, rather than to focus entirely on the design of navigation systems.

The specific objectives of the study are to:

- Summarise the different value related concepts and show how they may be applied within a driving context

- Measure the driver performance outcomes and variability over the course of an unfamiliar route using a benchmark information set

- Identify the key contextual factors related to the physical environment that influence the variance between observed and desirable outcomes

- Identify the value that additional or enhanced geographic information plays in maximising driver outcomes 


\section{How geographic information adds 'value'}

\subsection{Value concepts}

The term 'value' or 'added-value' is often used in relation to consumer products, and has a number of different definitions according to the theoretical background of the research. For example, in retailing and marketing Zeithaml (1988) defines perceived value as 'the consumer's overall assessment of the utility of a product [or service] based on perceptions of what is received and what is given' and describes how 'value represents a trade-off of the salient give and get components'. Sweeney and Soutar (2001) describe value as comprising dimensions of emotional, social and functional value. Lin et al. (2005) review different conceptions of value, and conclude that value comprises multiple 'give-get' components - and is measured in terms of those components - rather than being a construct which can be measured directly. Within HCI, Cockton (2004) has used the term 'value' to describe what is worthwhile for end users, and then later (2006) as a 'unifying concept for design'.

Different perspectives on 'value' come from Information Science where there are (1) a number of different definitions that can be employed, and (2) considerable challenges in the design and evaluation of information (Raban, 2007). Sheridan (1995) describes how information value is that which arises from using information - in terms of 'what one pays to acquire information together with what one earns by taking action based on it'. The importance (and complex context) of information value is demonstrated by Hollnagel (1988) when he describes the need to provide the right information at the right time for users, and the observation by Flach et al. (1998) that the challenge is to determine what 'right' means.

Ahituv et al. (1994) describe three perspectives on information value: normative (quantitative calculation based on probabilities and expected costs and payoffs); realistic or revealed (outcome measure, based on differences in performance); and subjective (individual judgement of its worth). They make the key point that no matter how information value is defined, 'it is a relative value, based on comparisons between payoffs gained under different sets of information'. Koops (2004) also describes how the value of information 'is not affected by variance in the possible states of the environment, but rather by variance in the available actions'. He highlights that value is derived from the potential to undertake difference forms of behaviour - if there is no possibility of an individual undertaking a different set of actions if supplied with 
information, then the value of that information is zero. This mirrors Bateson (1980), when he defines information as being 'any difference that makes a difference'.

It is possible to incorporate the notion of desired outcomes within an information value framework. Koops (2004) describes how 'the value of correct information ...... is the difference in payoff obtained when informed versus uninformed'. More specifically, Karim (1997) describes how the concept of the expected value of information (EVOI) is defined as the 'expected increase in the value (or decrease in the loss) associated with obtaining more information about quantities relevant to the decision process'. The expected value of information is therefore a measure of the importance of the uncertainty about a quantity in terms of the expected improvement in the decision that might be obtained from having additional information about it. In summary, an information value approach is being used within this study since a vehicle navigation system is an information appliance that is designed to impact on driver outcomes. The concept of realistic or revealed value is used, focussing on driver outcomes, and the term 'added-value' is used to describe the differences in driver outcomes resulting from different sets of geographical information.

\subsection{Application within a driving context}

Within a driving context, there has been surprisingly little explicit application of a value-based investigation of information provision to drivers, and associated outcome measures. This is despite the fact that navigating an unfamiliar route clearly displays the variance in possible driver actions that is needed for information value to be meaningful (Koops, 2004).

In relation to turn-by-turn navigation, a driver's basic need is for preview information that prepares a driver for the turning (e.g. lane keeping and speed control), identifying information to locate a turning, and confirming information that identifies whether a correct turning has been made (Burnett, 1998). A large number of studies have identified in general terms the geographic information that is useful for driver navigation. Drivers have stated preferences for road names, landmarks, junction layout, place names and road numbers (Burns, 1998; Burnett, 1998). In particular, good landmarks, including traffic lights, have been shown empirically to be effective for identifying the location of turnings (May and Ross, 2006; Ross et al., 2004; Burnett, 2000). 
However, there have been relatively few studies that have investigated how the context of the particular manoeuvre influences the geographic information that is, and is not useful in that situation. Frank (2003) describes how the level of knowledge a driver holds influences the level of content that is useful for navigation purposes. He also highlights that where information is available from the world, the same content within a message may have a lower information value.

Richter and Klippel (2004) have identified how navigation systems should adapt themselves according to localised contextual factors, and that instructions can be chunked as not all decision points need the same degree of attention from the driver. Lee et al. (2008) describe the need for contextual adaptation of vehicle navigation instructions. They imply (without explicitly stating) that the value of navigation information varies at manoeuvres, and that greater consideration is needed of what information is, and is not useful at specific geographical locations.

Sugiyama et al. (2001) describe a model where the demand (i.e. need) for navigation instructions is a function of the route non-linearity, the junction complexity (how many navigation choices) and the change of road width. The degree of the navigation demand is represented as a linear combination of these three factors, which will vary according to the manoeuvre.

Finally, the notion of affordances is highly relevant for decision making within a geographical context. The term was introduced by Gibson (1979) who investigated how people perceive their environment. He describes the affordances of the environment as 'what it offers the animal, what it provides or furnishes, either for good or ill'. He makes the key point that affordances are not physical properties - they have to be measured in relation to an individual or a situation. Affordances describe a relationship between people and objects/the environment, when an individual is attempting a specified task, and as will be discussed, can either help or hinder at manoeuvres.

\subsection{Operationalization of 'added-value'}

Within this study the concept of the expected value of information (Karim, 1997) is used. The information value perspective is appropriate because it enables a vehicle navigation system to be treated as a decision support tool, with a direct link to driver outcomes related to information provision. The expected value of information concept 
allows a desired set of outcomes to be defined - i.e. the level of driver performance that you would hope to achieve from the optimal information set being available to the driver.

The study sought to empirically investigate 'added-value' in relation to a benchmark information set - this being the information provided by a typical satellite navigation system that provides junction layout, distance-to-turn, and road name information to a driver. The outcomes were measured in relation to this information set (i.e. the driver performance resulting).

Since 'added-value' is the difference in outcomes arising from different information sets (Figure 1), the added-value in relation to an alternative (or theoretically feasible) set of outcomes can be derived from the benchmarking exercise. It can be seen that low added-value arises either where there is already sufficient information available to make decisions that lead to desired outcomes, or where there is little variation in the range of possible outcomes. In the case of driver navigation, information is typically provided to a driver when there are multiple navigation options, i.e. the driver has a direct influence on their outcomes. This can be contrasted with traffic information, where it may not be possible for a driver to pursue alternative courses of action - the traffic information may be extremely accurate, but of little or no value to the driver in terms of altered outcomes that arise.

By identifying where there is variance between the benchmarked and desired outcomes, the geographical context which differentiates these situations can be identified. It is then possible to identify where additional geographic cues are useful to a driver, where they do not add value, and what cues are useful. This can then contribute to the design of context-aware systems that present additional or alternative information to a driver, and minimise information presentation where it serves no useful purpose. 


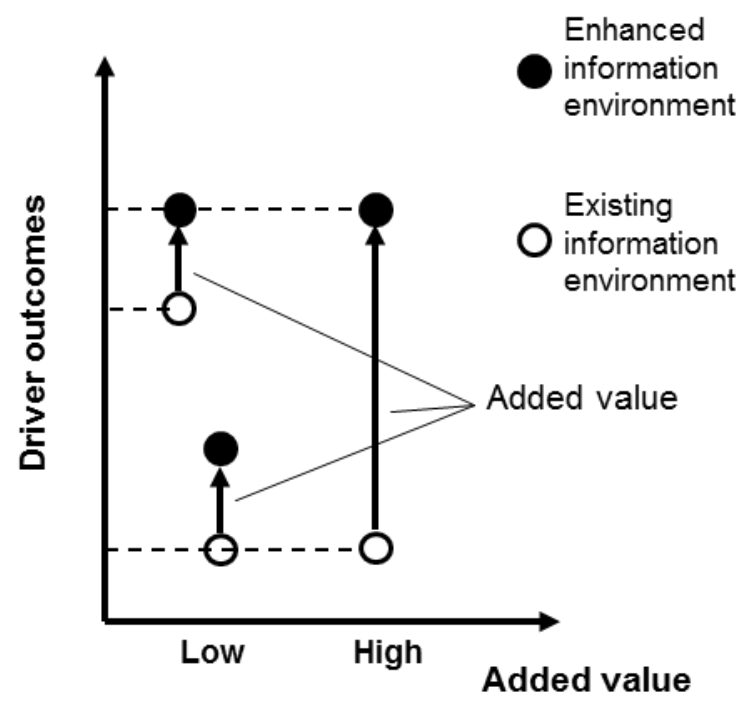

Figure 1. Added-value as a comparison of outcomes resulting from different information sets

\section{Method}

The rationale behind this study was to expose drivers to a range of potential navigation decision-making situations within a given information environment and determine their levels of performance in each of these situations. Their levels of performance would be compared to a set of 'desirable' outcomes in order to determine where additional value could be generated by an enhanced information environment, i.e. instructions which were more effective than those currently used by navigation systems. The study was therefore not a traditional experimental comparison of different interfaces - rather it was an empirical determination of performance under a range of geographic contexts, followed by analysis of how performance could be improved with a more optimal information set.

\subsection{Experimental route}

The experimental route was based around the south of Leicester, a city in the Midlands in the UK, with approximately 320,000 inhabitants (Table 1):

Table 1. The route characteristics

$\begin{array}{ll}\text { Total length } & 17.5 \mathrm{~km} \\ \text { No. of driver decision points } & 37\end{array}$




\begin{tabular}{ll}
\hline Road description & $\begin{array}{l}10 \% \text { dual carriageway and 90\% single } \\
\text { carriageway } \\
\end{array}$ \\
Built environment & not city centre) retail/commercial \\
Total driving time & Approx. 40 minutes \\
Speed limits & Majority $50 \mathrm{kph}$ \\
\hline
\end{tabular}

The route was chosen to encompass a range of different driver decision points. These were geographical locations where a lack of navigation information would normally result in a navigation error in relation to the desired direction of travel, or navigation uncertainty. A highly complex, meandering route was chosen, where successful route following required the assimilation of turn-by-turn information provided by the vehicle navigation system - the participant was therefore making multiple navigation decisions based on the information presented to them, rather than driving towards a specified destination. This represents a navigation task (or part thereof) where external navigation cues such as road signs may not be useful (although they may be present) for example the 'last mile' of route following. Where road signs were present, they were potentially useful as landmarks rather than information cues, since they were visually prominent and situated on the approach to manoeuvres. The driver decision points comprised a variety of junction types, including: traffic-light controlled junctions, roundabouts, T-junctions/cross roads requiring the driver to give way, and turnings off the major road. This enabled an analysis per junction type, described below. A full list of manoeuvres on the route is shown in the Appendix.

\subsection{Participants and apparatus}

Sixteen participants took part in the trial. At the recruitment participant stage, all potential participants were asked their level of familiarity with different localities within Leicester; only those who stated they were unfamiliar with the test area were invited to take part. Participants were all over 21 years (mean $=44.3$ years), with selfreported normal vision, had held a clean driving licence for at least three years (mean $=22.8$ years), and drove regularly (mean annual mileage $=12800$ miles).

Each participant drove an instrumented LandRover Freelander (a compact sports utility vehicle) and navigated the route using a modified satellite navigation system. The main geographic information the navigation system presented was a direction arrow integrated into a junction overview, and a distance countdown bar that showed 
the distance to the turn (starting at 500 metres and counting down to zero in $50 \mathrm{~m}$ increments). The satellite navigation system also displayed the name of the current road and the name of the road being turned into. The standard auditory distance-toturn instructions were replaced by recorded prompts to ensure that distance-to-turn and direction information were presented consistently throughout the route. The auditory output consisted of up to three verbal prompts as follows: a Preview 1 message given at 500m; a Preview 2 message given at 200m; a Final auditory tone (beep) given at 50 $\mathrm{m}$ to the manoeuvre. If the preceding manoeuvre was closer than $300 \mathrm{~m}$, the initial auditory message was omitted. This presentation strategy is typical of that for most current Vehicle Navigation Systems.

\subsection{Experimental design}

Real-time data were not collected at five of the 37 manoeuvres en-route due to either the close proximity of turns, or the necessity to stop the vehicle in order to reprogramme destinations. The experimental design in this chapter was therefore a 32 way (manoeuvre location) within-subject design with 16 participants. To enable analysis per junction type, data were aggregated to produce a four-way within subjects design based on differentiation according to the type of junction as shown in Table 2 below.

Table 2. Categorisation of junction type

\begin{tabular}{llll}
\hline Cat. & Description & Freq. & Key feature \\
\hline 1 & $\begin{array}{l}\text { Traffic light controlled } \\
\text { junction }\end{array}$ & $\mathrm{N}=3$ & $\begin{array}{l}\text { Traffic lights can act as a prominent } \\
\text { landmarks at the junction }\end{array}$ \\
2 & Roundabout & $\mathrm{N}=7$ & $\begin{array}{l}\text { Signposts for identification, driver } \\
\text { required to give way }\end{array}$ \\
3 & $\begin{array}{l}\text { T-junction or non-traffic } \\
\text { light crossroad }\end{array}$ & $\mathrm{N}=7$ & Driver required to stop \\
4 & $\begin{array}{l}\text { Turning off the current } \\
\text { road }\end{array}$ & $\mathrm{N}=14$ & $\begin{array}{l}\text { The need for locating turning and } \\
\text { correct speed control } \\
\text { (Not analysed) }\end{array}$ \\
\hline 5 & Other & $\mathrm{N}=1$ &
\end{tabular}

Due to the constraints of driving an actual route with a real navigation system, it was not possible to randomise or balance the within-subjects factor, i.e. all participants completed the manoeuvres in a set order. Therefore it might be expected that either a 
learning effect would occur (and performance would increase throughout the trial), and/or that fatigue effects would occur (and performance would decrease throughout the trial). This would increase variability within the data, and could result in differential impact of junction type on the dependent variables. Learning effects were mitigated as far as possible by incorporating a familiarisation and training period of approximately 45 minutes prior to driving the experimental route. Fatigue effects were mitigated by limiting the total length of the trial to 1 hour 30 minutes. In addition, the Appendix shows how junction types were relatively evenly distributed throughout the route. All trials took place mid-morning or mid-afternoon (off-peak traffic conditions) to minimise the variability of the impact of traffic level on the study.

\subsection{Dependent variables}

Dependent variables were defined as those which captured performance on the aspects of both concurrent tasks that were of interest: driving safety (Srinivasan, 1999), and navigation performance (Burns, 1998). Driver confidence was also used as an outcome measure, but this measure can also be interpreted as whether the resources available from the driver are sufficient to resolve the navigational uncertainty at a manoeuvre.

Navigation performance was assessed on the basis of participants committing actual or near navigation errors at each manoeuvre. An actual navigation error was one where the participant made an incorrect navigation decision at the manoeuvre, and either turned too early, turned too late, or did not complete any turn when required. A near navigation error was one where the participant demonstrated a clear intention to take an incorrect turn - by indicating, changing lanes, and/or slowing down on approach to a turning which was not that desired.

Driving errors were used as a measure of driving safety. Driving errors while completing each manoeuvre were assessed by a UK Driving Standards Agency Approved Driving Instructor who accompanied each participant during the trial (and was unaware of the exact nature of the trial). This mirrored the use of a driving instructor by Zaidel and Noy (1997) to rate 'quality of driving'. Errors were recorded by the driving instructor using a checklist that employed six error categories as used in the UK Driving Examination (Table 3):

Table 3. Error categories used for driving performance assessment 
Use of mirrors and rear observation when signalling, changing direction and speed Appropriate use of indicators

Response to signs and signals including traffic signs, road markings, traffic lights, other road users

Junctions, including speed of approach, observation, turning left or right and cutting corners Positioning in normal driving and lane discipline

Awareness and planning

In addition, severity of each driving error committed by the participant at each manoeuvre was recorded as 'minor', 'serious' or 'dangerous' using a checklist developed in conjunction with the driving instructor. A minor error was one that was only significant if it was habitual (e.g. cuttings corners at junctions). A serious error was one in which potential danger to road users had occurred; a dangerous error was one where actual danger had occurred (e.g. where evasive action had to take place to avoid an accident).

Driver confidence was measured in real time after the driver had received each verbal instruction from the navigation system (at approximately 450, 150 and 30 m preceding each manoeuvre). Immediately after the driver had received each of these navigation instructions, they were prompted by the experimenter, who asked 'confidence?’ In response the driver gave a single word answer of 'high', 'medium', or 'low' to indicate their confidence with knowing where to turn and being able to complete that manoeuvre successfully. After completing each manoeuvre, participants were again prompted by the experimenter and gave an additional confidence rating of 'high', 'medium, or 'low' to indicate their confidence that they had taken the correct turn.

\subsection{Desired levels of performance}

The value-add approach within this study requires the comparison between actual and 'desired' outcomes, arising from differing sets of geographical information. The actual outcomes are being measured empirically, being those arising when a driver uses the information provided by typical Vehicle Navigation Systems. The desired outcomes can be defined as an acceptable level of performance in relation to navigation errors, driving errors and driver confidence, as shown in Table 4. 
Table 4. Desired levels of performance

\begin{tabular}{ll}
\hline Performance metric & Desired performance level \\
\hline \multirow{2}{*}{ Navigation errors } & $\begin{array}{l}\text { Zero actual or near navigation errors per manoeuvre as } \\
\text { defined in Section 4.1 below }\end{array}$ \\
Zero driving errors per manoeuvre, as defined in Section \\
4.2 below \\
High levels of confidence at Preview 1, Preview 2, Final \\
and Post manoeuvre points
\end{tabular}

\subsection{Procedure}

Participants were told that the trial was investigating their reaction to a Vehicle Navigation System. They completed consent forms and a demographic questionnaire, and then spent five minutes while stationary finding a comfortable driving position, adjusting mirrors and familiarising themselves with the car controls. They then undertook a 25 minute practice drive on mostly urban roads, without using the Vehicle Navigation System. Participants completed eight manoeuvres using the Vehicle Navigation System, and a further five where they also gave confidence ratings at each manoeuvre as described in Section 3.4. All participants were offered (but rejected) additional practice. They were then asked to drive the test route, in their normal driving style, using the Vehicle Navigation System, which presented visual and auditory navigation information at each manoeuvre. Approaching each junction, the driver gave up to three pre-manoeuvre confidence ratings, prompted by the presentation of information by the Vehicle Navigation System (Section 3.4), and one post-manoeuvre confidence rating having completed the turning. In practice, drivers routinely gave this rating without the prompting of the experimenter described in Section 3.4. If not, participants were prompted once only, and if not provided, it was treated as missing data.

Due to the study taking place within a real road environment, at some manoeuvres it was difficult to regain the route if participants took an incorrect turning. For this reason, if participants looked certain to take an incorrect turning, they were prompted to continue on the correct route by the experimenter before they did so. This was still classified as a navigation error. 
Whilst approaching, and undertaking each manoeuvre, the type and severity of any driving errors were recorded by the driving instructor (sitting in the front passenger seat) using the predefined checklist. Navigation errors and confidence ratings were recorded by an experimenter sitting in the rear. In addition, a second experimenter in the rear controlled the presentation of verbal instructions via the Vehicle Navigation System. At the end of the route, one of the experimenters drove the vehicle back to the start.

\section{$4 \quad$ Analysis and results}

Collected data is presented based on navigation errors, driving errors and driver confidence. Effects are identified according to the overall effect of manoeuvre, and the distinction between different junction types (Table 2).

\subsection{Navigation performance}

The (actual or near) navigation errors committed at each manoeuvre en-route are shown in Figure 2, which groups manoeuvres (labelled M1-M37, described in the Appendix) into junction categories (labelled C1-C5, described in Table 2). The bars show the total error score for all participants. A Cochran's Q test for related binary responses (' 0 ' = no navigation error, ' 1 ' = actual or near navigation error at a manoeuvre) confirmed that the committal of navigation errors at manoeuvres by participants was significantly impacted by the manoeuvre they were undertaking $\left(\chi^{2}(31)=292.098, p<.001\right)$. Aggregation of errors according to junction category (Table 2) showed that committal of navigation errors was related to the junction category (Friedman test for four related samples, $\chi^{2}(3)=35.413, p<.001$ ).

Differences between the four junction categories are shown in Figure 3. 


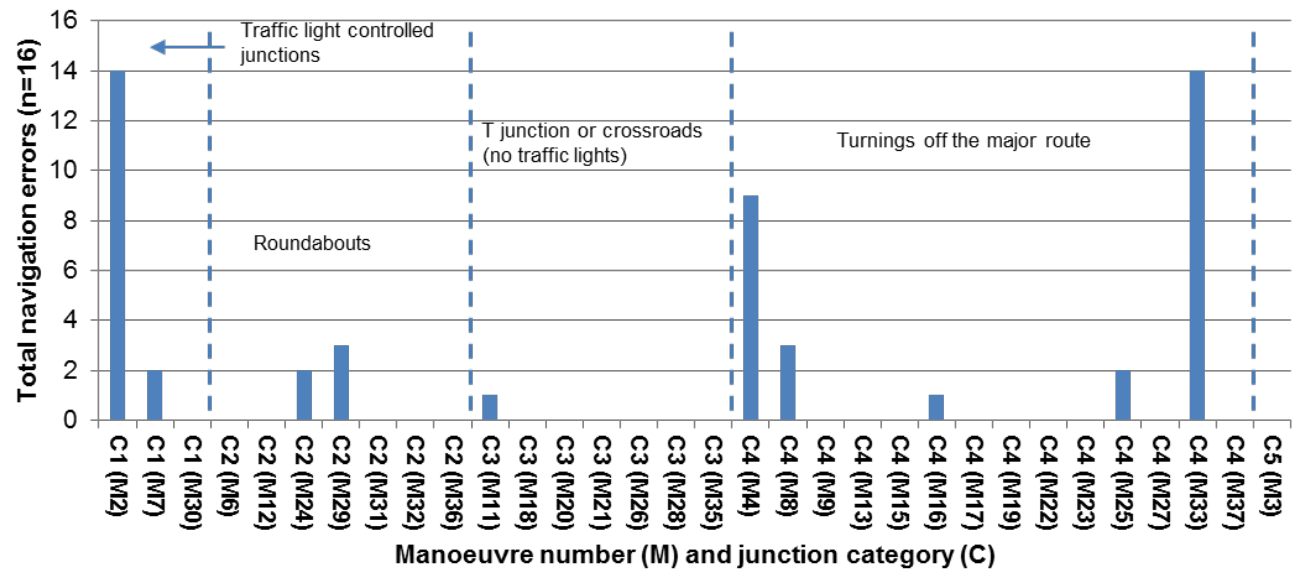

Figure 2. Number of navigation errors committed at each manoeuvre

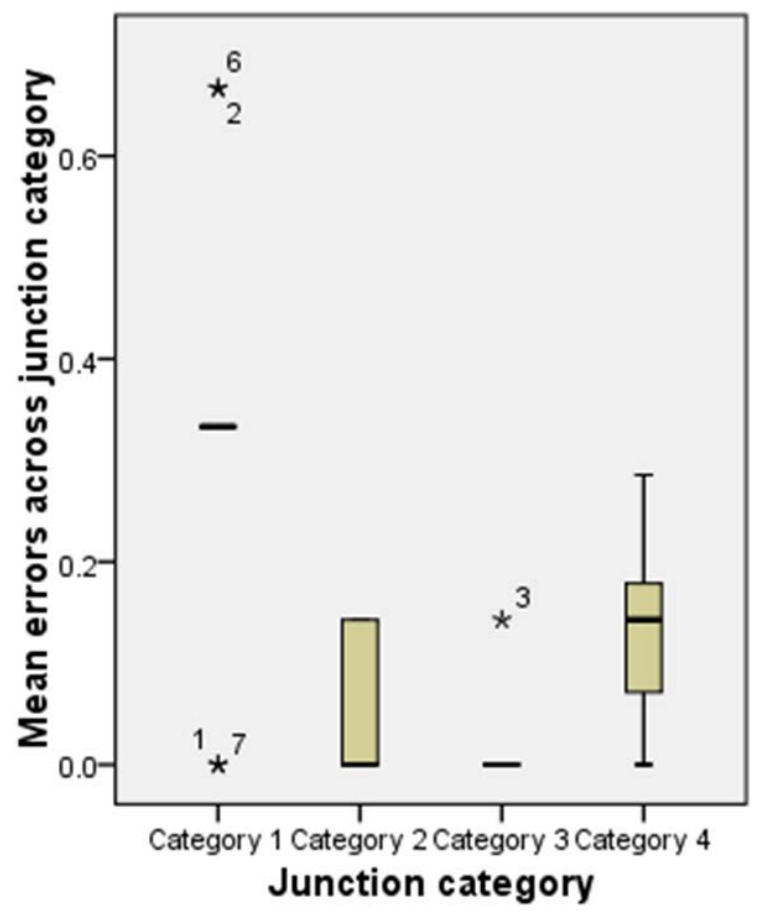

Figure 3. Boxplot of navigation errors according to junction category 


\subsection{Driving errors}

In consultation with the driving instructor, a coding scheme was employed where errors classified as minor, serious or dangerous were apportioned values of 1,5 or 10 ; this was based on the driving assessment of habitual minor errors representing dangerous driving. The total error score $(E)$ for each participant at each manoeuvre was calculated as: $\mathrm{E}=f_{\mathrm{m}}+5 f_{\mathrm{s}}+10 f_{\mathrm{d}}$, where $f_{\mathrm{m}}, f_{\mathrm{s}}$, and $f_{\mathrm{d}}$ represent the number of minor, serious and dangerous errors committed by a participant at a manoeuvre.

Figure 4 shows how the error score (total for all participants), and division of error types varied according to manoeuvre, with manoeuvres grouped into junction types as above. The total driving error score was significantly impacted by the particular manoeuvre (Friedman non-parametric for related samples, $\chi^{2}(31)=95.530, p<.001$ ). Analysis by junction category (Figure 5) showed that the total driving error score was impacted differentially by junction category (Friedman non-parametric for related samples, $\left.\chi^{2}(3)=14.089, p=.003\right)$.

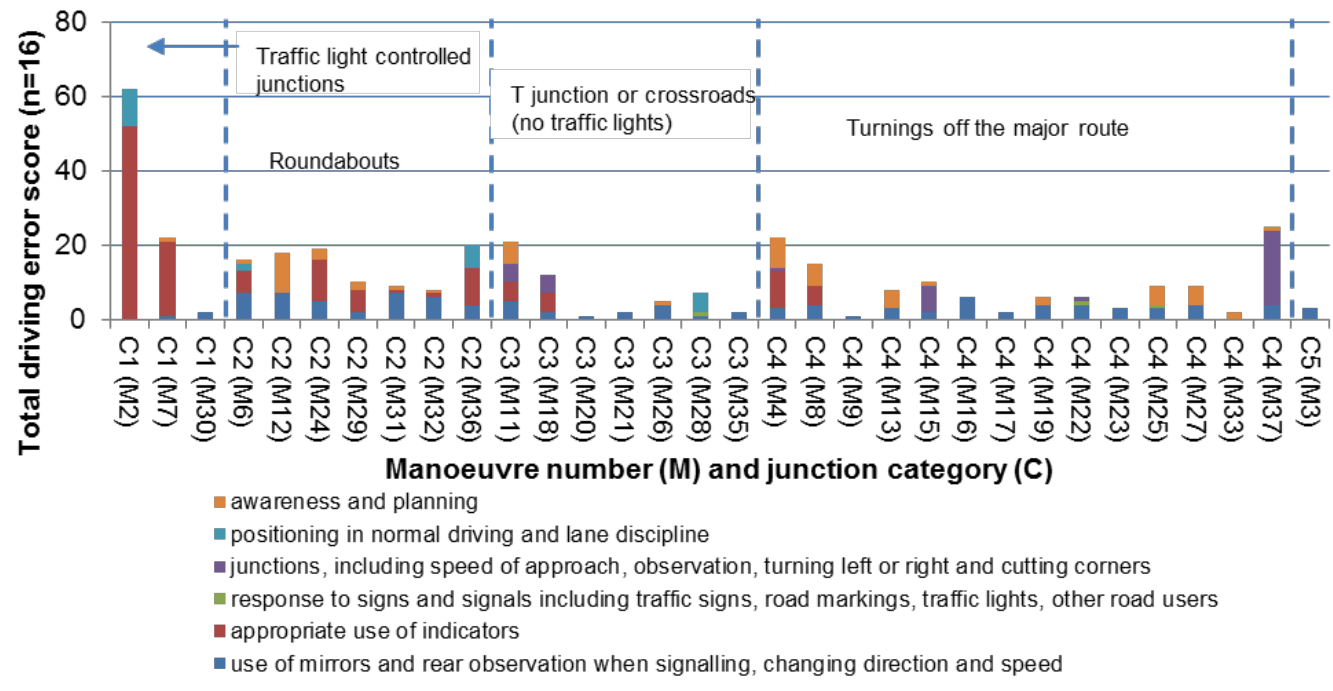

Figure 4. Number and type of driving errors committed at each manoeuvre 


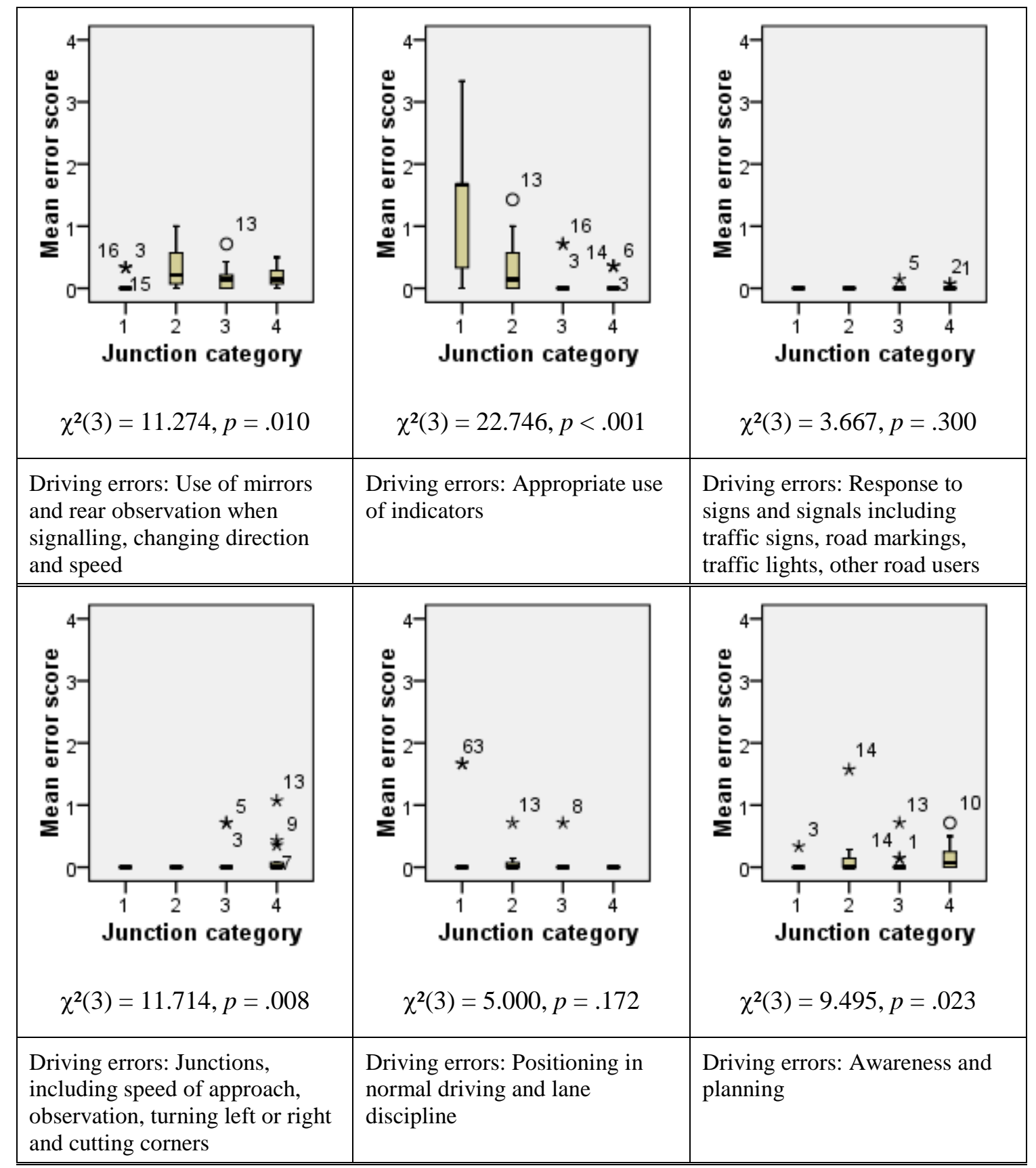

Figure 5. Boxplot of each driving error type, by junction category

\subsection{Driver confidence}

All confidence ratings were coded as follows: 'high':3; 'medium':2; 'low':1 respectively. Figure 6 shows the mean changes in confidence over the course of the manoeuvre (Preview 1, Preview 2, Final and Post), for each of the four junction categories. The $y$-axis reference lines represent confidence ratings of high, medium and low respectively. 


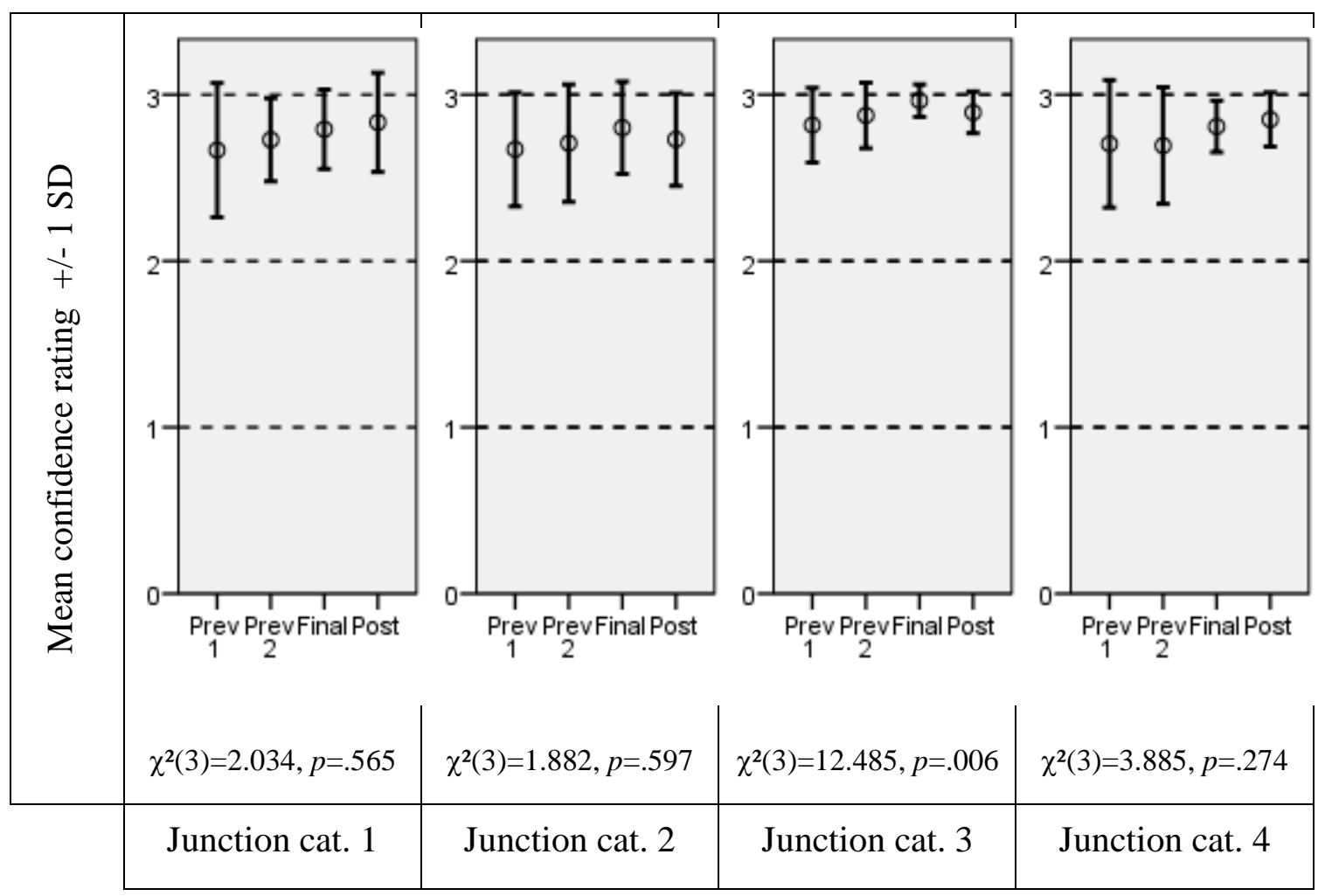

Figure 6. Changes in confidence levels during manoeuvre, per junction category

Taking each junction category in turn, the changes in confidence over the course of the manoeuvre were significant for Category 3 only, shown above. Comparing confidence between the different junction categories, there were no significant differences at the Preview $1\left(\chi^{2}(3)=6.044, p=.109\right)$ and Preview $2\left(\chi^{2}(3)=7.500, p=.058\right)$ points, but significant differences at the Final approach point $\left(\chi^{2}(3)=13.394, p=.004\right)$ and at the Post manoeuvre point $\left.\chi^{2}(3)=1.812, p=.008\right)$. An analysis was also undertaken of the changes in confidence over each of the 32 manoeuvres on route; this is shown in Figure 7. All statistics for driver confidence were based on Friedman non-parametric tests for related samples. 


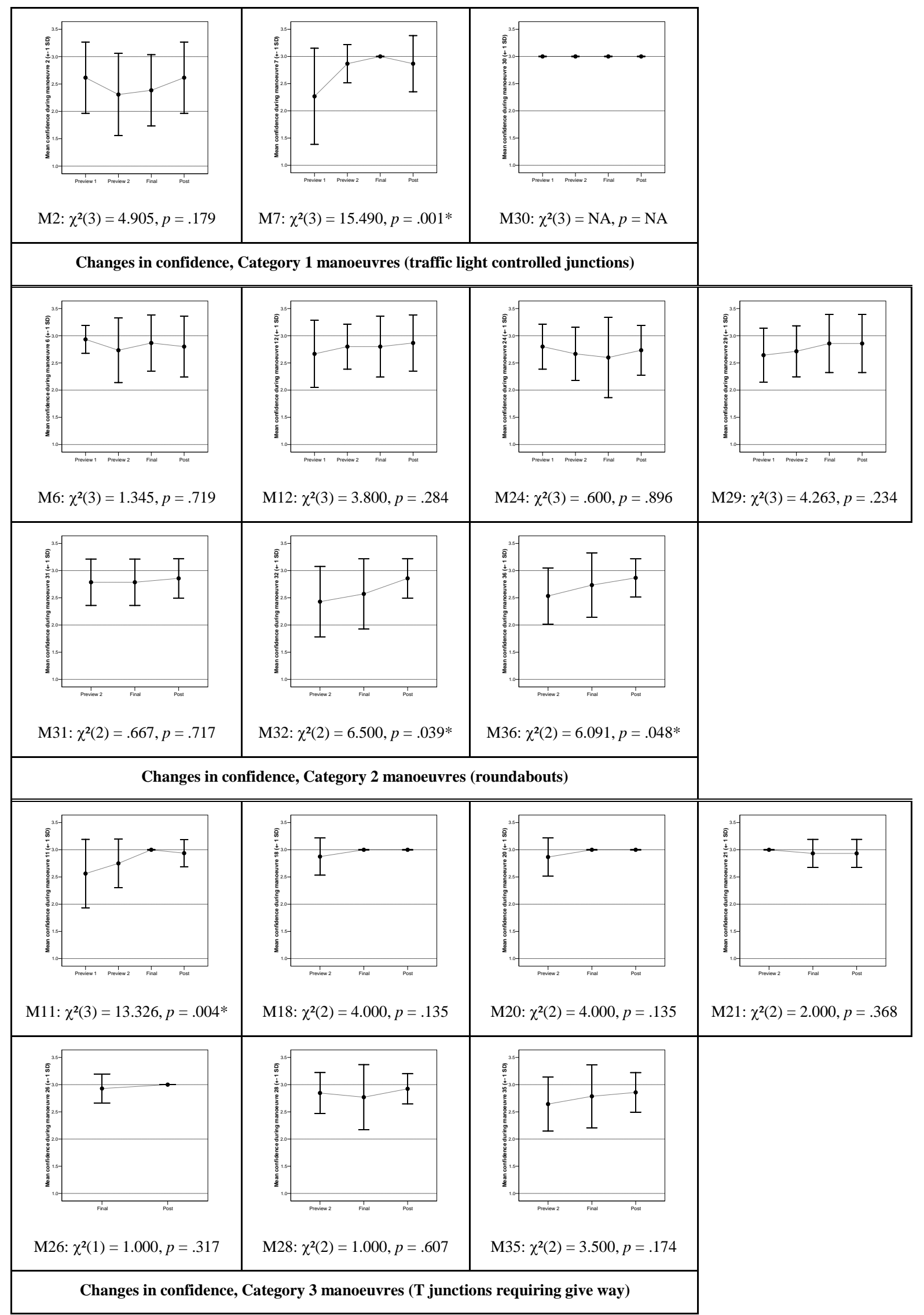




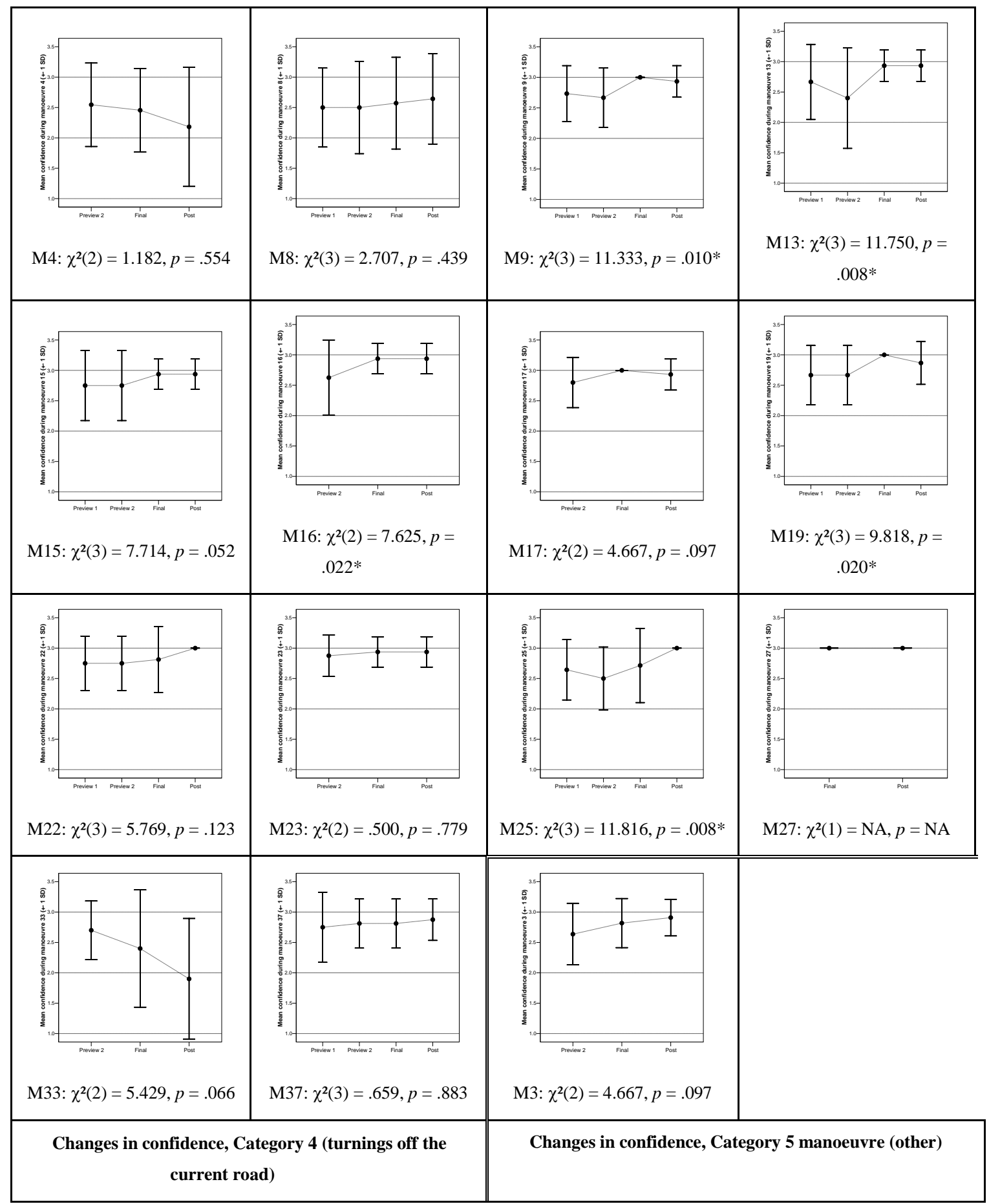

Figure 7. Changes in confidence levels for each manoeuvre 


\subsection{Correlation between dependent variables}

Mean driver confidence at manoeuvres was moderately inversely related to navigation errors at manoeuvres $(\mathrm{N}=32$, Spearman $\rho=-.553, p=.001)$. Mean driver confidence was weakly inversely related to driver errors $(\mathrm{N}=32$, Spearman $\rho=-.358, p=.045)$. Driving errors were weakly positively correlated to navigation errors $(\mathrm{N}=32$, Spearman $\rho=.417, p=.018)$.

\subsection{Comparison of visual glances}

A video recording was made of each driver's face throughout the trial, which enabled limited video analysis. A comparison of the number of glances made to the navigation system at the first (M2) and final (M37) manoeuvres showed that there was no significant difference in the number of glances to the navigation system at these two manoeuvres (Wilcoxon signed ranks, $\mathrm{Z}=-1.281, p=.200$ ).

\section{Discussion of dependent variables}

The study involved a relatively small number of participants (16). It is recognised that this weakens the strength of the conclusions, and it is recommended that the study is considered a pilot that can lead to more substantial studies of a similar nature.

\subsection{Navigation errors}

Table 4 specifies the desired level of navigational errors as zero. This is based on a knowledgeable passenger who would be able to give pre-warning, lane-keeping and context-dependent turn instructions based on effective geographic information.

Figure 2 shows that empirically, there was considerable variation in the number of navigation errors (actual or near) committed during the study. At 22 manoeuvres, there were no navigation errors. In contrast, three manoeuvres accounted for $73 \%$ of the navigational errors made, with 14 out of 16 participants committing a navigation error at each of manoeuvres M2 and M33, and nine participants making an error at M4. A differentiation by junction category showed that the occurrence of navigational errors was related to the junction category, and results presented in Figures 2 and 3 suggest that Category 3 junctions ( $\mathrm{T}$-junctions where the driver had to give way) produced the fewest navigational errors. By reference to Figure 2 and the junction description in Appendix, two other factors emerge for those manoeuvres where navigation errors occurred. Navigation errors occurred where there were several turnings relatively close 
to each other, and where the required turning was more minor than others close-by, and particularly where the required turning was partially obscured (e.g. by the road geometry or parked vehicles). A ‘drawing in’ effect appeared to occur where the driver's expectations were that they should take the more major road, being either prior to or after the desired turning. This effect was noted by Burnett (1998), and is also consistent with the concept of physical affordances (Gibson, 1979) where the visual appearance of the environment around an individual suggests a natural course of action to the individual. Navigation errors did not occur where there was a combination of a simple directional choice to be made, and where either the junction was visible from a distance, or the design of the road layout required the driver to slow down or stop. Acting as a decision support system, the driver was therefore presented with reduced variability in the decision outcomes, and the ability to apply sufficient resources in the multi-tasking environment.

\subsection{Driving errors}

Table 4 defines the desired levels of driving errors as zero. Figure 4 shows that there were two manoeuvres (M9 and M20) where there was only one minor error committed by the entire participant group ( $\mathrm{N}=16)$, and a further five manoeuvres where only two minor errors were committed by the participant group; zero errors is therefore a feasible benchmark.

Figure 4 shows wide variability in the number and type of driving errors committed at manoeuvres, highlighting the influence that characteristics of manoeuvres have on driving performance. Differentiation by junction category (Figure 5) shows how some driving errors were more prevalent than others, and how different driving errors tended to be committed at different types of junctions. The analysis of aggregated driving errors is complicated by the (necessary) increased weighting given to serious and dangerous errors - for example the high driving error score of 25 at M37 (Figure 4) was comprised of four minor errors relating to the use of mirrors and rear observation, one minor error relating to awareness and planning, but dominated by one dangerous and two serious errors relating to manoeuvring at the junction.

Although there were driving errors relating to the use of mirrors and rear observations, for all junction types (which can indicate participants habitually committing these types of errors throughout the course of a drive), these were more prevalent at 
roundabouts. Inappropriate use of indicators occurred at traffic light controlled junctions (category 1) and roundabouts; however the effect at traffic-light controlled junctions was dominated by the level of errors occurring at M2 (and discussed below). Driving errors related to speed of approach and vehicle control at junctions were highest for turnings off the major road (category 4); however this type of error only occurred at four of the manoeuvres within this category, and the total was dominated by one serious error at M15 and two serious and one dangerous error at M37. The highest level of errors relating to awareness and planning again occurred at turnings off the major road, with a combination of minor and serious errors.

Although there are some general findings relating to junction categories, the committal of driving errors is more readily understood when the geographical context of individual manoeuvres is considered. Driving errors at M2 occurred because participants attempted to take a preceding major turn which was a filter lane (also shown by the high levels of navigation errors, above. Even though M2 incorporated traffic lights - a good landmark for driver wayfinding (May and Ross, 2006; Ross et al., 2004), the visual scene at M2 was cluttered and the preceding turn was more visually prominent. A similar effect occurred at M7. In contrast, at M30 (the final traffic light controlled junction), there were only two minor driving errors committed due to this junction being visible from approximately $500 \mathrm{~m}$.

M4 was a turning into a narrow, partially obscured side road. This resulted in driving errors related to awareness, planning and use of indicators (and also navigation errors discussed above) due to the participants not identifying the location of the turning, and being drawn towards a more clearly identifiable major turn approximately 50m past the desired turning.

It was apparent that low levels of driving errors occurred at the majority of the Tjunctions. Even though these were not as visible as the traffic-light controlled junctions, the design of the road layout, and the visual cues inherent in the manoeuvre imposed a level of speed control on the driver. In contrast, M37 was a minor turning off a fast flowing more major road, and there were insufficient visual cues or features within the road environment to promote early speed reduction. This resulted in driving errors related to speed control on approach to the manoeuvre. 


\subsection{Driver confidence}

A driver undertaking a manoeuvre should have high levels of confidence as they approach the manoeuvre, and also having completed the manoeuvre. Figure 7 shows the levels of driver confidence at up to three preview points, and also post manoeuvre, with manoeuvres grouped according to junction category. A test of changes in confidence throughout the manoeuvre is given in each case. If the preceding manoeuvre was at less than 450m the first preview point was omitted, and if less than 200m, then second preview point was also omitted. Figure 6 aggregates manoeuvres according to junction category, and shows changes in mean confidence ratings as a driver progresses through a manoeuvre, for each type of junction. Error bars (as opposed to boxplots) are shown as it presents more clearly the changes in confidence levels. Although there is a general increase in confidence as the participants progressed through a manoeuvre, this is only significant for $\mathrm{T}$ junctions (category 3 ) due to the relatively low variance in the data.

The plots of individual manoeuvres (Figure 7) show clearly the variance in the data both between different manoeuvres and also between participants for specific manoeuvres. At manoeuvres M27 and M30, mean overall confidence was 3, i.e. all participants gave a rating of 'high' for all of the pre and post-manoeuvre ratings. At these manoeuvres, the required turning was highly visible at all of the confidence rating points - for example M30 was a traffic light-controlled T junction preceded by a long straight road, where the manoeuvre was clearly visible even at the preview 1 point at 500m from the manoeuvre. In contrast, there were three manoeuvres where overall confidence was 2.5 or less: M2, M4 and M33. At M2, there was a preceding crossroads and participants appeared unsure of which turning they were required to take. At M4 and M33, the required turn was a small road off a more major route: in both cases it was partially obscured and participants were not confident of identifying the location of the required turn using the distance information provided by the navigation system. These manoeuvres also correspond to those points where participants committed the most navigation and driving errors (discussed above). Manoeuvre M7 (category 1 - traffic light controlled junction) shows a typical (and in this case significant) increase in confidence as a driver approaches a turning, due to the increasing visibility of the junction. This also shows the wide inter-subject variability in confidence on initial approach (approx. 500m to the manoeuvre. Manoeuvre M8 
(category 4 - turning off the major road) shows relatively low levels of confidence throughout a manoeuvre due to the turning being relatively obscured throughout approach. Manoeuvre M33 (also category 4) shows how confidence actually fell during the course of the manoeuvre, as the small turning did not become more visible as the driver approached, and it was followed (35m) by a more visible major turning that participants had expected to take. This also shows how the driver was uncertain whether they had actually taken the correct turning after having completed the manoeuvre (Post point). Similarly, at several junctions (e.g. M13 and M19), driver confidence remained relatively low until the final preview point at 50m from the manoeuvre, where they could actually see the junction clearly.

\subsection{Relationship between measures}

Sections 5.1 to 5.3 above have considered each of navigation errors, driving errors and driver confidence separately. However, it is possible that driver confidence has remained high even though navigation errors have been made (i.e. a driver's mistaken belief that they have taken the correct turning). Alternatively, a driver may trade off navigation and driving performance if information enables successful navigation to the detriment of driving errors. Visual comparison of Figures 2 and 7, and a plot of confidence versus navigation errors, shows that driver confidence was low at manoeuvres where navigation errors were being made. The correlation of driver confidence and navigation errors (Section 4.4) suggests that drivers were aware that they were making navigation errors, which tended to reduce their confidence that in relation to that turning. This is despite the experimenter tending to prompt the participant in order to reduce the occurrences of actually navigating off-route. In addition, the lack of a discernable relationship between driving errors and navigation errors (Section 4.4) leads to the conclusion that drivers were not consistently committing driving errors in order to maximise navigation performance.

\subsection{Impact of experimenter prompting}

Drivers were prompted by the experimenter if they were about to take particular incorrect turnings (this happened on occasionally), where recovery of the route was difficult. It is therefore possible that participants learnt, over the course of the trial, to pay less attention to the navigation device (due to the likelihood of the experimenter correcting them). In addition, they could have become progressively more confident 
post-manoeuvre that they had taken the correct turning (since they would know whether they had taken an incorrect turning). However, there was no evidence that either of these behavioural changes took place. The visual glance comparison in Section 4.5 suggests participants did not seem to be paying less attention to the navigation system at the end of the trial. In addition, the manoeuvre resulting in lowest post-manoeuvre driver confidence was M33, which occurred $90 \%$ of the way through the route.

\section{The potential to add value}

'Desired' outcomes can be described in terms of specific outcome measures, and 'added-value' in this context can be defined as the difference in outcomes due to differing information sets. It is then possible to identify the extent to which performance on these three measures can be improved. This is the 'added-value' that can be provided to a driver, over and above that provided by distance-to-turn and junction layout information within a typical navigation system. In addition, by investigating the geographical context where driver outcomes are less than desired, it is possible to identify (1) the context where additional geographical information can be provided to the driver in order to improve their levels of performance and (2) where the information from a navigation system and the additional geographical cues available in the environment are sufficient. In this latter case, additional information will have little or no value, since it will not result in any changes in driver outcomes. Sections 5.1 to 5.3 above have shown how navigation errors, driving errors and driver confidence have varied considerably at different manoeuvres, when standard distanceto-turn and junction layout information have been used to navigate an unfamiliar route. It is important to remember that in all cases, the information from the navigation system has acted to supplement the information already available in the road environment. Within this study, a meandering route was chosen that meant that road signage was not useful for navigation purposes. However, at roundabouts and trafficlight controlled junctions, road signs would help identify the location of a junction, which would help explain the lack of driving errors related to speed control at these two categories of junctions.

At manoeuvres such as M2, M4, M33 and M37 there is considerable potential to add value by supplementing the information environment. This could increase navigation 
performance, driving performance and/or driver confidence. In contrast, at many manoeuvres such as M20, M27 and M30, an enhanced information environment adds no value to the driver's decision making, since the driver outcomes are already at or close to the expected or desired level. Additional information does not aid the driver's decision making, and unnecessarily impacts on the resource-limited driver. 'Less' can be 'more’ (Marcus, 2004; Meilinger et al., 2007).

Although there were some effects that could be attributed to categories of junctions, the differentiation between types of manoeuvres failed to explain the wide variability in driver outcomes that was observed. There were several examples of manoeuvres which appeared similar, but resulted in widely differing driver outcomes. An example was manoeuvres M2, M7 and M30, which were all traffic light controlled junctions, and where navigation errors ranged from zero to 14, the driving error score ranged from 2 to 62, and driver confidence for M30 was high throughout the entire manoeuvre. Similarly for turnings off the major route, navigation errors also ranged from zero to 14, driving error scores from 1 to 25, and confidence levels at specific turnings were shown to increase, decrease and remain at high levels throughout. The individual geographical context, rather than the junction category, can better explain the variability in observed outcomes (and hence the potential to add value in these situations). There were several key factors which appeared to differentiate the driver outcomes. The first is the advance visibility of the junction. A junction can be obscured by parked cars, street furniture, or the road topography, and obscuration clearly played a role in all three driver outcomes. On approach to a manoeuvre, a driver would have expectations relating to the visibility of a manoeuvre. As a driver approaches a manoeuvre, they expect it to become more visible, and when this does not occur, driver confidence on approach can actually reduce (see M20, M27 and M30 in Figure 7 for examples of this). There are two strategies that can be employed in this case. The junction itself can be made easier to identify by a driver. Several authors (e.g. May and Ross, 2006; Burnett, 2000) have shown how presenting good landmarks on a navigation system is beneficial to a driver as it enables identification of a manoeuvre without reliance on distance-to-turn judgements. Effective landmarks are highly visible, easily recognised and described, readily represented by icons, and usefully situated at or on approach to junctions. Examples of good landmarks are traffic lights, pedestrian crossings and large bridges over the road. It is also possible to 
use highly visible branded Points of Interest (e.g. fast food restaurants and petrol stations). They have the advantage of being more readily available as objects on geographic databases, as well as there being commercial motivation for maximising their visibility to drivers, and ensuring geographic database information is up to date. An alternative option is to present photo-realistic views of distinctive objects or views. However this implies that objects are contained within geographic databases as photographs or 3D models; in addition, it is not clear whether the likely increase in driver distraction will be outweighed by any navigation benefits.

The second strategy is to manage the driver expectations for manoeuvres which are not highly visible. If a navigation system indicates to a driver that a manoeuvre is not visible until they are close to it, and can present other information (e.g. preceding landmarks or location of other prior turnings) to indicate approach to the manoeuvre, then it is likely that a driver's confidence on approach can be maintained. The information needed for this is relatively standard topography, which is already available on geographic databases. For example, road curvature, elevation data and building footprints could be used to identify those junctions which are obscured on approach.

The second factor which explained the variability in driver outcomes was the presence of proximate preceding or subsequent manoeuvres, especially if these were more major than the desired turning. Distance judgement by humans is relatively poor (Böök and Gärling, 1980) and the drawing in effect noted by Burnett (1998) was demonstrated, which caused drivers to either attempt to turn too early (M2) or too late (M4, M33). The information needed to counter these effects is an indication to the driver of the presence of these other turns, but with the desired turning also clearly shown. This may also need to show how the driver should not be following the major traffic flow. In effect, this is saying to the driver 'don't take the more obvious turning' - i.e. counteracting the impact of natural affordances (Gibson, 1979) on driver behaviour. A combination of topographic data, road classifications, and traffic flows would be needed to identify where this ‘drawing in' effect would be likely. The final major factor that helped explain the variance in driver outcomes was the impact of the natural topography and affordances of the road network. In some situations these acted to promote the desired driver behaviour - for example Tjunctions were more visible than turnings off the major road, and also inherently 
promoted speed reduction on approach to the manoeuvre. In other situations, the nature of the geographical environment promoted an increase in speed, when the desired behaviour was speed reduction on approach to a manoeuvre. An example of this was at M37 on a relatively fast section of road where drivers tended not to reduce their speed sufficiently on approach, even though the manoeuvre was highly visible. In these situations, the driver can be provided with guidance on safe approach speeds, or explicit instructions to reduce speed on approach. Alternatively speed reduction can be promoted through road layout design, as is commonly seen.

The findings of the study are consistent with the assertion by Lee et al. (2008) that the context, and situational importance of information, are important. The situationalbased design that they describe is based around the design of map-based displays, whereas this study was based on the concept of turn-by-turn instructions. The results of this study are not completely consistent with the limited literature that deals with context or complexity within driver navigation. The potential to add value is clearly impacted by the number of decision choices and the clues available (Raubal and Egenhofer, 1998) but appears poorly predicted by the (pedestrian rather than driving) model of Sugiyama et al. (2001) which does not take into account the visibility of the desired turning and the influences that proximate turnings will have on navigation decisions. The contextual influences on the value added by navigation information at manoeuvres appear to be better explained by the affordances of Gibson (1979) including the information and misinformation that he describes - and a consideration of whether heuristic-driven decision making (e.g. a driver making an incorrect assumption to follow the traffic flow or take a more major turning) leads to navigation errors.

\section{Conclusions}

The aims of this article were to demonstrate how a 'value-adding' framework can be used within a user-centred approach to geographic information design, and to highlight how geographic information can improve the performance of drivers navigating an unfamiliar route.

The difference between an 'added-value' approach and a standard usability approach is that it focuses more explicitly on the differences in outcomes arising from different information sets. An added-value approach can promote comparison of actual with 
desired levels of performance. It also takes into account the opportunity for changes in outcomes, since value is dependent on the variance in possible outcomes from using different information sets. An added-value approach also explicitly considers other geographic cues that may be available, and determines whether providing additional information actually contributes to enhanced outcomes within a resource-limited usage context.

The overall conclusion from this study is that navigation systems would benefit from being more context-aware, consistent with the observation by Richter and Klippel (2004). Systems should move towards the model of an informed passenger providing context-relevant navigation information to the driver when it adds value to the driver, and not providing information when it is unnecessary - the contextual adaptation of behaviour described by Dey (2001). Section 6 has discussed specific situations where more tailored geographic information is useful. Navigable map databases can already provide much of this context including: potential obscuration of manoeuvres due to road topography; proximity of similar manoeuvres; presence of more major turns that may create a 'drawing in' effect; junction design and give way requirements that promote speed reduction; the direction of travel of the more major route.

In summary, an 'added-value' perspective can potentially shift the design focus for geographical information presentation. Usability is of course still important, since information that cannot be understood and used by the intended user is not information (Badenoch et al., 1994; Harter, 1992). However, rather than the issue being: 'what information can we deliver?' and 'can the end user understand it?' a useful consideration for the designer is: 'what are our desired outcomes?', 'does information presentation actually serve a useful purpose?' and 'what is needed in this particular context?'.

\section{Acknowledgement}

This study was funded by the EPSRC, UK. The author also wishes to thank his colleagues who helped with aspects of this study, and in particular Tracy Ross, Gary Burnett and Nick Smith. 


\section{References}

Ahituv, N., Neumann, S., and Riley, H. N. (1994). Principles of information systems for management (Vol. 4). Dubuque IA: W.C. Brown.

Badenoch, D., Reid, C., Burton, P., Gibb, F., \& Oppenheim, C. (1994). The value of information. In M. Feeney \& M. Grieves (Eds.), The value and impact of information, 9-77, London: Bowker, Saur.

Bateson, G. (1980). Mind and Nature - A Necessary Unity. New York: Bantam Books.

Burnett, G. (2000). “Turn right at the traffic lights”: The requirement for landmarks in vehicle navigation systems. Journal of Navigation, 53(3), 499-510.

Burnett, G. E. (1998). “Turn right at the King’s Head”: Drivers’ requirements for route guidance information. Unpublished PhD thesis, Loughborough University, UK.

Burns, P. C. (1998). Wayfinding errors while driving. Journal of Environmental Psychology, 18(2), 209-217.

Böök, A., \& Gärling, T. (1980). Processing of information about location during locomotion: Effects of a concurrent task and locomotion patterns. Scandinavian Journal of Psychology, 21(3), 185-192.

Cockton, G. (2004). Value-centred HCI. NordiCHI 2004, 149-160, ACM.

Cockton, G. (2006). Designing worth is worth designing. Proceedings of the 4th Nordic conference on Human-computer interaction: changing roles, 165-174, ACM.

Dey, A. K. (2001). Understanding and Using Context. Personal and Ubiquitous Computing, 5(1), 4-7.

Fastenmeier, W., Haller, R., \& Lerner, G. (1994). A preliminary safety evaluation of route guidance comparing different MMI concepts. In ERTICO (Ed.), Towards an Intelligent Transport System. Proceedings of the First World Congress on ATT and IVHS. Vol. 4, 1750-1757, Artech House: Boston.

Fastreza, P., \& Haue, J.-B. (2008). Editorial: Designing and evaluating driver support systems with the user in mind. Int. J. Human-Computer Studies, 66(3), 125-131.

Flach, J. M., Vicente, K. J., Tanabe, F., Monta, K., \& Rasmussen, J. (1998). An Ecological Approach to Interface Design. Human-System Interaction: The Sky's No Limit. Human Factors and Ergonomics Society 42nd Annual Meeting, Chicago, Illinois (1), 295-299, The Human Factors and Ergonomics Society.

Frank, A. U. (2003). Pragmatic information content. How to measure the information in a route description. In M. Goodchild, M. Duckham, \& M. Worboys (Eds.), 
Perspectives on geographic information science, 47-68, London: Taylor and Francis.

Gibson, J. J. (1979). The ecological approach to visual perception. Boston, MA: Houghton-Mifflin.

Goodchild, M. F. (2009). Geographic information systems and science: today and tomorrow. Annals of GIS, 15(1), 3-9.

Green, P., Levison, W., Paelke, G., \& Serafin, C. (1995). Preliminary Human Factors Design guidelines for driver information systems. Technical Report No. FHWARD-94-087. (Vol. 94). Springfield, VA.: US Department of Transportation, Federal Highway Administration.

Harter, S. P. (1992). Psychological relevance and information science. Journal of the American Society for Information Science, 43(9), 602-615.

Harvey, C., Stanton, N. a, Pickering, C. a, McDonald, M., \& Zheng, P. (2011). A usability evaluation toolkit for In-Vehicle Information Systems (IVISs). Applied Ergonomics, 42(4), 563-74.

Hollnagel, E. (1988). Information and reasoning in intelligent decision support systems. In E Hollnagel, G. Mancini, \& D. D. Woods (Eds.), Cognitive engineering in complex dynamic worlds. London: Academic Press.

Jackson, P. G. (1998). In search of better route guidance instructions. Ergonomics, 41(7), 1000-1013.

Karim, A. S. (1997). Assessing the Value of Information in a Decision Support System Context: A Simulation Study. In J. Carey (Ed.), Human Factors in Information Systems: The Relationship between User Interface Design and Human Performance, 67-81, Greenwich, Connecticut, USA: Ablex Publishing Corporation.

Koops, M. (2004). Reliability and the value of information. Animal Behaviour, 67(1), 103-111.

Kun, A. L., Paek, T., Medenica, Ž., Memarović, N., \& Palinko, O. (2009). Glancing at personal navigation devices can affect driving: experimental results and design implications. Proceedings of the 1st International Conference on Automotive User Interfaces and Interactive Vehicular Applications, 129-136, ACM.

Lansdown, T. C., Brook-Carter, N., \& Kersloot, T. (2004). Distraction from multiple in-vehicle secondary tasks: vehicle performance and mental workload implications. Ergonomics, 47(1), 91-104.

Lavie, T., Oron-gilad, T., \& Meyer, J. (2011). Aesthetics and usability of in-vehicle navigation displays. Journal of Human Computer Studies, 69(1-2), 80-99. 
Lee, J., Forlizzi, J., \& Hudson, S. E. (2008). Iterative design of MOVE: A situationally appropriate vehicle navigation system. International Journal of Human-Computer Studies, 66(3), 198-215.

Lin, C. H., P.J.Sher, \& Shih, H. Y. (2005). Past progress and future directions in conceptualizing customer perceived value. International Journal of Service Industry Management, 16(3-4), 318-336.

Lunenfeld, H. (1989). Human factor considerations of motorist navigation and information systems. Vehicle Navigation and Information Systems Conference, 1989. Conference Record, 35-42, IEEE.

Marcus, A. (2004). The next revolution: vehicle user interfaces. Interactions, 11(1), 40-47.

May, Andrew J., \& Ross, T. (2006). Presence and Quality of Navigational Landmarks: Effect on Driver Performance and Implications for Design. Human Factors: The Journal of the Human Factors and Ergonomics Society, 48(2), 346-361.

May, A., \& Ross, T. (2006). Presence and quality of navigational landmarks: effect on driver performance and implications for design, Human Factors, 48(2), 346-361.

Meilinger, T., Hölscher, C., Büchner, S. J., \& Brösamle, M. (2007). How Much Information Do You Need? Schematic Maps in Wayfinding and Self Localisation. Lecture Notes in Computer Science, 4387/2007, 381-400.

Raban, D. R. (2007). User-centered evaluation of information: a research challenge. Internet Research, 17(3), 306-322.

Raubal, M., \& Egenhofer, M. (1998). Comparing the Complexity of Wayfinding Tasks in Built Environments. Environment and Planning B, 25(6), 895-913.

Richter, K. F., \& Klippel, A. (2004). A model for context-specific route directions. Spatial Cognition IV. Reasoning, Action, and Interaction: International Conference Spatial Cognition 2004. Lecture Notes in Computer Science . Springer, Berlin., 3343, 58-78.

Ross, T, May, A. J., \& Grimsley, P. J. (2004). Using Traffic Light Information as Navigational Cues: Implications for Navigation System Design. Transportation Research Part F: Traffic Psychology and Behaviour, 7(2), 119-134.

Sheridan, T. B. (1995). Reflections on Information and Information Value. IEEE Transactions on Systems Man and Cybernetics, 25(1), 194-196.

Srinivasan, R. (1999). Overview of some human factors design issues for in-vehicle navigation and route guidance systems. Transportation Research Record, (1694), 20-26. 
Sugiyama, H., Hasegawa, T., \& Doi, M. (2001). A pedestrian navigation system based on a navigation demand model. 8th World Congress on Intelligent Transport Systems [CD], Sydney, Australia.

Sweeney, J., \& Soutar, G. N. (2001). Consumer perceived value: the development of a multiple item scale. Journal of Retailing, 77(2), 203-220.

Walker, G. H., Stanton, N. A., \& Young, M. S. (2001). Where Is Computing Driving Cars? International Journal of Human-Computer Interaction, 13(2), 203-229.

Wierwille, W. W., Antin, J. F., Dingus, T. A., \& Hulse, M. C. (1989). Visual attentional demand of an in-car navigation display system. In A. G. Gale (Ed.), Vision in vehicles II, 307-316, London: Elsevier Science.

Zaidel, D. M., \& Noy, Y. I. (1997). Automatic versus interactive vehicle navigation aids. In Y. I. Noy (Ed.), Ergonomics of Intelligent driver interfaces, 287-307, Lawrence Erlbaum Associates, Mawaha, NJ.

Zeithaml, V. A. (1988). Consumer perceptions of price, quality and value: A meansend model and synthesis of evidence. Journal of Marketing Research, 52(3), 2-22. 


\section{Appendix - Description and categorization of manoeuvres}

\begin{tabular}{|c|c|c|c|}
\hline Man & $\begin{array}{l}\text { Junct } \\
\text {. cat. }\end{array}$ & Nature of turning & Distinguishing features \\
\hline M2 & C1 & Turning right off the major road & Traffic light controlled crossroads \\
\hline M3 & C5 & Continuing on the same road as it bears left & $\begin{array}{l}\text { No visual indication of a change in } \\
\text { road }\end{array}$ \\
\hline M4 & $\mathrm{C} 4$ & Turning right off the major road & $\begin{array}{l}\text { Turning into narrow, partially } \\
\text { obscured turning }\end{array}$ \\
\hline M6 & $\mathrm{C} 2$ & Turning left onto more major road & Give way at roundabout \\
\hline M7 & $\mathrm{C} 1$ & Turning right off the more major road & Traffic light controlled crossroads \\
\hline M8 & $\mathrm{C} 4$ & Turning left off the more major road & \\
\hline M9 & $\mathrm{C} 4$ & Turning left off the more major road & \\
\hline M11 & C3 & Left at $\mathrm{T}$ junction onto more major road & Give way \\
\hline M12 & $\mathrm{C} 2$ & $\begin{array}{l}\text { Right at mini roundabout onto more minor } \\
\text { road }\end{array}$ & Give way \\
\hline M13 & $\mathrm{C} 4$ & Turning right off current road & \\
\hline M15 & $\mathrm{C} 4$ & Turning left off the more major road & Accelerating on approach to turn \\
\hline M16 & $\mathrm{C} 4$ & Turning right off the more major road & \\
\hline M17 & $\mathrm{C} 4$ & Turning left off the current road & \\
\hline M18 & C3 & $\begin{array}{l}\text { Turning right at } \mathrm{T} \text { junction onto more major } \\
\text { road }\end{array}$ & Give way \\
\hline M19 & $\mathrm{C} 4$ & Turning right off the more major road & \\
\hline M20 & $\mathrm{C} 3$ & Turning left at cross roads & Give way \\
\hline M21 & C3 & $\begin{array}{l}\text { Turning left at } \mathrm{T} \text { junction onto more major } \\
\text { road }\end{array}$ & Give way \\
\hline M22 & $\mathrm{C} 4$ & Turning right off the more major road & \\
\hline M23 & $\mathrm{C} 4$ & Turning right off the current road & \\
\hline M24 & $\mathrm{C} 2$ & $\begin{array}{l}\text { Turning right off the major road at mini } \\
\text { roundabout }\end{array}$ & Give way \\
\hline M25 & $\mathrm{C} 4$ & Turning right off the more major road & \\
\hline M26 & $\mathrm{C} 3$ & Turning left at $\mathrm{T}$ junction & Give way \\
\hline M27 & $\mathrm{C} 4$ & Turning left off the current road & Close to preceding turn \\
\hline M28 & C3 & $\begin{array}{l}\text { Turning right at } \mathrm{T} \text { junction onto more major } \\
\text { road }\end{array}$ & Give way \\
\hline M29 & $\mathrm{C} 2$ & Straight over mini roundabout & Give way \\
\hline M30 & C1 & $\begin{array}{l}\text { Turning left at } \mathrm{T} \text { junction onto more major } \\
\text { road }\end{array}$ & $\begin{array}{l}\text { Traffic light controlled T junction, } \\
\text { highly visible from a distance }\end{array}$ \\
\hline M31 & $\mathrm{C} 2$ & $\begin{array}{l}\text { Turning left at roundabout onto more minor } \\
\text { road }\end{array}$ & $\begin{array}{l}\text { Continuing in ahead direction, close } \\
\text { to preceding turn }\end{array}$ \\
\hline M32 & $\mathrm{C} 2$ & Veering left at mini roundabout & Give way, close to preceding turn \\
\hline M33 & $\mathrm{C} 4$ & Turning left off the more major road & $\begin{array}{l}\text { Turning into narrow, partially } \\
\text { obscured turning, close following turn }\end{array}$ \\
\hline M35 & C3 & $\begin{array}{l}\text { Turning right at } \mathrm{T} \text { junction onto more major } \\
\text { road }\end{array}$ & Give way \\
\hline M36 & $\mathrm{C} 2$ & Right at roundabout onto more major road & Give way, close to preceding turn \\
\hline M37 & $\mathrm{C} 4$ & Turning right off the more major road & \\
\hline
\end{tabular}

Note that no data collected were collected at manoeuvres $1,5,10,14,34$ 